\title{
Linerless Plastic Container Closure
}

National Cancer Institute

\section{Source}

National Cancer Institute. Linerless Plastic Container Closure. NCI Thesaurus. Code C96130.

A closure that incorporates a specific molded-in feature such as rings, plugs or flexible sections. These features achieve a seal by conforming to one or more of the sealing surfaces on the container neck finish. 